\title{
Mapping Agronomic Traits in a Wild Barley Advanced Backcross-Nested Association Mapping Population
}

\author{
Liana M. Nice, Brian J. Steffenson, Thomas K. Blake, \\ Richard D. Horsley, Kevin P. Smith, and Gary J. Muehlbauer
}

\begin{abstract}
Crop improvement relies on the ability to utilize novel genetic variation. Six-rowed malting barley (Hordeum vulgare L. subsp. vulgare) developed in the US Midwest has an especially narrow genetic base. Therefore, developing strategies to widen the genetic base in barley is important for continued crop improvement. A wild barley [Hordeum vulgare L. subsp. spontaneum (K. Koch) Thell.] advanced backcross-nested association mapping (AB-NAM) population was developed to assess wild-barley-derived alleles in an elite spring six-rowed malting barley background. The $796 \quad \mathrm{BC}_{2} \mathrm{~F}_{4: 6}$ lines in the AB-NAM were derived from 25 wild barley accessions backcrossed to the cultivar Rasmusson. Because the AB-NAM design minimizes the deleterious and unadapted traits of the wild barley parents, the population was screened in five field environments for the agronomic traits: days to heading, height, productive tiller number (PTN), test weight, and yield. The number of loci identified ranged from two (PTN, the trait with the lowest heritability) to 19 (height). Domestication-related genes were identified for each trait, particularly the photoperiod gene $\mathrm{Ppd}-\mathrm{H} 1$ for days to heading, height, and PTN and the nonbrittle Btr1/Btr2 loci for test weight and yield. Only a single variant showed beneficial variation for yield from a wild barley allele, but positive effects were identified for the other traits examined, including positive variants for test weight on chromosomes $1 \mathrm{H}$ and $3 \mathrm{H}$. The AB-NAM population is a novel resource to map agronomically important traits associated with wild barley alleles.
\end{abstract}

L.M. Nice, K.P. Smith, and G.J. Muehlbauer, Dep. of Agronomy and Plant Genetics, Univ. of Minnesota, St. Paul, MN 55108; B.J. Steffenson, Dep. of Plant Pathology, Univ. of Minnesota, St. Paul, MN 55108; T.K. Blake, Dep. of Plant Sciences and Plant Pathology, Montana State Univ., Bozeman, MT 59717; R.D. Horsley, Dep. of Plant Sciences, North Dakota State Univ., Fargo, ND 58108; G.J. Muehlbauer, Dep. of Plant Biology, Univ. of Minnesota, St. Paul, MN 55108. Received Oct 2. 2016. Accepted 9 Jan. 2017. `Corresponding author (mueh1003@ umn.edu). Assigned to Associate Editor Linghe Zeng.

Abbreviations: AB-NAM, advanced backcross-nested association mapping; AB, advanced backcross; BLUP, best linear unbiased predictor; PTN, productive tiller number; QTL, quantitative trait loci; SNP, single-nucleotide polymorphism; WBDC, Wild Barley Diversity Collection.

$\mathrm{W}$ ILD BARLEY, the progenitor of cultivated barley, is known to be a rich source of genetic and phenotypic diversity (Ellis et al., 2000; Russell et al., 2016). Over the course of crop domestication and improvement, the diversity of cultivated barley has been eroded by forces such as selection and drift (Rostoks et al., 2006). Today, cultivated barley populations retain an estimated $40 \%$ of the alleles present in wild barley populations (Ellis et al., 2000). Strong selection and inbreeding without the introduction of new sources of diversity have led to reduced genetic diversity in breeding populations (Condón et al., 2008; Fu and Somers 2009; Muñoz-Amatriaín et al., 2010). Six-rowed Midwestern malting barley has an especially narrow genetic base (Rasmusson and Phillips, 1997). This limited diversity exposes barley breeding programs to the risk of insufficient allelic diversity to overcome future disease threats, environmental changes, or resource limitations.

Barley breeders have several target traits for improvement including yield, malting quality, disease resistance, and abiotic

Published in Crop Sci. 57:1199-1210 (2017).

doi: $10.2135 /$ cropsci2016.10.0850

(C) Crop Science Society of America 5585 Guilford Rd., Madison, WI 53711 USA This is an open access article distributed under the CC BY-NC-ND license (http://creativecommons.org/licenses/by-nc-nd/4.0/). 
stress resistance. Historically, exotic sources of germplasm have been used primarily to introgress qualitative traits such as disease resistance (Hajjar and Hodgkin, 2007). Large-effect alleles for important traits have a clear economic value, justifying the time and resources needed to identify and introgress these beneficial alleles from unadapted germplasm. The use of exotic material for more complex traits including yield and quality characteristics has been more limited (Fischbeck, 2003). Yield is a classic complex trait influenced by many genetic and environmental factors. Furthermore, yield is not a trait that has necessarily undergone selective pressure in wild populations. Because yield is influenced by many genes and because there is extensive genetic diversity present in wild populations, it is possible that alleles for improved yield exist in otherwise unadapted germplasm. With the decreasing cost of genotyping and improving bioinformatic and genetic analysis techniques, the prospects for identifying and using diverse germplasm for improving complex traits are expanding.

Identifying alleles for complex traits can be challenging, particularly when working with unadapted germplasm. Besides having seed substantially lighter than cultivated barley, wild barley seed is difficult to harvest and process because of its brittle rachis and tough awns (Pourkheirandish and Komatsuda, 2007). The history of domestication and improvement in cultivated barley has removed many of these deleterious traits from the breeding pool, and a large performance gap exists between wild and cultivated barley. Thus, it is difficult to characterize the genetic value of unadapted germplasm directly. To minimize the confounding effects of these deleterious traits, advanced backcross (AB) quantitative trait loci (QTL) analysis was developed (Tanksley and Nelson, 1996). This technique involves QTL mapping in a population that has been created by repeatedly backcrossing an unadapted accession to an adapted variety and then selfing to create recombinant inbred lines. The backcross generations minimize the number of deleterious traits in any single individual, but given sufficient individuals in the population, the exotic alleles can be adequately sampled and analyzed. Furthermore, if beneficial alleles are identified, these alleles are already partially introgressed into an adapted background. This technique has been used by barley researchers to identify beneficial alleles from wild barley sources for many traits of interest including yield and agronomic traits (Li et al., 2005; Von Korff et al., 2006; Gyenis et al., 2007; Eshghi et al., 2013), malting quality (Von Korff et al., 2008; Schmalenbach and Pillen, 2009; March et al., 2012), disease resistance (Von Korff et al., 2005; Yun et al., 2006; Li et al., 2006), abiotic stress tolerance (Saal et al., 2011; Hoffmann et al., 2012; Schnaithmann and Pillen, 2013; Kalladan et al., 2013), and root traits (Naz et al., 2014).
Two major drawbacks to the AB strategy are that alleles from only one unadapted germplasm source are sampled, and that relatively few recombination events are present in these mapping populations, resulting in relatively low mapping resolution (Wang and Chee, 2010; Nice et al., 2016). Association mapping is a technique that generally circumvents these limitations by using the historic linkage disequilibrium in diverse populations to identify marker trait associations (Rafalski, 2002). But, association mapping with widely unadapted germplasm can be logistically difficult, and it is often limited to traits such as disease resistance that can be scored at the seedling stage (Steffenson et al., 2007; Roy et al., 2010). Recently, multiparent approaches that involve more intricate mating designs than biparental population have been developed and implemented in several model organisms (Churchill et al., 2004; Kover et al., 2009; Huang et al., 2011; King et al., 2012) and crop species (Yu et al., 2008; Stupar and Specht, 2013; Mace et al., 2013; Schnaithmann et al., 2014). While the designs of these populations vary, they all aim to incorporate a larger amount of diversity than biparental mapping populations while minimizing the downsides of association mapping techniques: low power from low allele frequencies and confounding effects of cryptic population structure (Myles et al., 2009; Morrell et al., 2012).

The resolution and power of multiparent populations allow for the assessment of complex traits like yield in diverse germplasm. To explore the genetic architecture and availability of beneficial alleles that contribute to yield and yield-related traits in wild barley derived germplasm, we analyzed a previously developed AB-NAM panel derived from 25 wild barley parents each backcrossed twice to a single cultivated barley cultivar Rasmusson (Nice et al., 2016). Our objectives were (i) to assess the genetic architecture of yield and yield-related traits in a wild barley derived mapping population and (ii) to identify loci conveying beneficial effects from wild barley germplasm.

\section{MATERIALS AND METHODS Plant Materials}

The wild barley AB-NAM population is composed of $796 \mathrm{BC}_{2} \mathrm{~F}_{4: 6}$ lines derived from backcrossing 25 diverse wild barley lines to the cultivar Rasmusson (Nice et al., 2016). Families ranged in size from 27 to 39 individuals. Rasmusson is a six-rowed spring malting barley that was selected as the recurrent parent because of its favorable agronomic and malting characteristics (Smith et al., 2010). The diverse parents were selected from the 318 wild barley accessions in the Wild Barley Diversity Collection (WBDC) (Steffenson et al., 2007) based on genotypic diversity. All AB-NAM lines exhibit the six-rowed spike morphology and successfully produce seed in a spring-planted environment. Details about the parents used and the process of developing the AB-NAM population can be found in Nice et al. (2016). 


\section{Genotyping}

Parental lines were genotyped with the Illumina iSelect 9K single-nucleotide polymorphism (SNP) platform (Comadran et al., 2012) and exome capture sequenced (Mascher et al., 2013b). The AB-NAM lines were genotyped with a custom 384 Illumina GoldenGate SNP assay that maximized the differentiation between wild and Rasmusson alleles and were distributed throughout the genome (379 markers passed quality controls). The higher density marker datasets (9K SNP platform and exome capture sequence) were projected onto the AB-NAM lines using the 379 genotyped markers as a scaffold as described in Nice et al. (2016). The Muñoz-Amatriaín et al. (2014) 9K iSelect consensus map was used for imputing SNP markers, and the Mascher et al. (2013a) Morex $\times$ Barke POPSEQ map was used for imputing sequence variants, for a total of 4022 iSelect SNP markers (3520 unique bins) and 263,531 sequence variants (126,303 unique bins). Analysis of WBDC103 did not produce high-quality sequence alignments, and therefore this population was excluded from trait mapping analysis. To test for seed purity in the germplasm when grown in the field, five randomly selected lines in each of the two 2012 field environments were genotyped using the same 384-SNP platform.

\section{Field Trials and Trait Measurements}

The AB-NAM population was grown in an augmented, type- 2 field design (Lin and Poushinsky 1985) in five environments over 2 yr: Crookston, MN (CR12) and St. Paul, MN (SP12) in 2012 and Crookston, MN (CR13), Fargo, ND (ND13), and Bozeman, MT (MT13) in 2013. Plot sizes were as follows: for Minnesota trials, $8 \mathrm{~g}$ seeded in two $1.5 \mathrm{~m}$ rows spaced $0.3 \mathrm{~m}$ apart; for the North Dakota trial, 55 g seeded in 1.5- by $2.4-\mathrm{m}$ plots; for the Montana trial, $20 \mathrm{~g}$ seeded in 1.8 - by $0.6-\mathrm{m}$ plots. Rasmusson was grown as a repeated check in the center of each three- by 5-plot block. In 2012, cultivars Conlon and Harrington were grown as secondary repeated checks in each of eight randomly selected blocks. In 2013, cultivars Robust and Tradition were used as secondary checks. To fill the remaining plots in the 900-plot design, 21 to $33 \mathrm{AB}-\mathrm{NAM}$ lines were used as duplicated entries. Field designs in 2012 included blocking in columns $\times$ heading date to facilitate harvest of lines with large variation in maturity. These included early, middle, late, and unknown heading date blocks. Entries were assigned to blocks based on field-collected data in the summer of 2011. The blocking $\times$ heading date design was not repeated in 2013 .

Traits measured included heading date (all environments), PTN (CR12, SP12, CR13), height (all environments), yield (all environments), and test weight (ND13, MT13). Heading date was measured as the number of days from planting where $50 \%$ of the plot exhibited $50 \%$ spike emergence from the boot. Productive tiller number was measured as the number of tillers with grain producing spikes in a $0.5-\mathrm{m}$ section of the middle of a single plant row. Height was measured on a representative plant in the plot as the centimeters from the base to the top of the spike, excluding the awns, $\sim 1 \mathrm{wk}$ after heading. Plots were mechanically harvested after end trimming. Threshed, cleaned seed from each plot was weighed, and yield measurements were converted to kilograms per hectare. Test weight was measured on $0.118-\mathrm{L}$ samples and converted to grams per liter.

\section{Estimating Heritability and Partitioning Trait Variance}

When necessary, trait measurements were corrected for field spatial variability using a moving average correction approach. Moving average shape design and subsequent value adjustments were performed using the mvngGrAd $\mathrm{R}$ package (Technow, 2011). For each trait, an optimized moving average window was identified that minimized the variance of primary checks, secondary checks, and duplicated AB-NAM lines. A deviation from the environment mean was calculated for each plot based on the mean of the window surrounding the plot, and the plot value was adjusted according to this deviation. After spatial correction within environments, a multivariate mixed model was fit in ASReml-R (Butler et al., 2009) with random effects fit for line, environment and line $\times$ environment interaction, and best linear unbiased predictors (BLUPs) were obtained, resulting in a single trait value for each AB-NAM line. Broad-sense heritability for each trait was calculated on a line mean basis across environments. Pearson correlation coefficients were calculated for each trait pair.

\section{Trait Mapping}

Genome-wide association analysis was performed using multienvironment BLUPs for each trait as described in Nice et al. (2016). The GWAS function in the rrBLUP R package (Endelman, 2011) was used to calculate marker-trait associations using the EMMAX/P3D approximation method (Kang et al., 2010; Zhang et al., 2010). Because there was negligible population structure, a $K$ mixed model was used to account for markerbased relatedness. A bootstrapping approach was taken, whereby 25 individuals were sampled from each of the 24 families with imputed sequence variants for a total of 600 individuals used for each mapping iteration. This sampling process and the subsequent trait mapping were performed 100 times. A false discovery rate threshold of 0.05 was used for calling significant associations, and a minor allele frequency threshold of 0.013 (10 individuals) was used to minimize spurious associations from low-frequency variants. Marker allele substitution effects were estimated by passing a single marker to the mixed.solve function in the rrBLUP R package (Endelman 2011; Mohammadi et al., 2015). To determine an overall significance measure, the $-\log (p$-value $)$ results, along with the marker effect estimates for marker-trait associations were averaged across significant bootstrap sampling replications. Those associations that occurred in $<5 \%$ of samples were not reported. Independent loci were assumed when a gap of $>5 \mathrm{cM}$ appeared between significantly associated markers.

\section{Data Accessibility}

The datasets supporting the results of this article are available in the Tritceae Toolbox repository (https://triticeaetoolbox. org/barley/). To access data, enter "WBIP" into the left-hand "Quick search..." box. Clicking on "Trial" will bring up links to phenotypic and genotypic data experiments. To locate exome capture variant calls for parents and imputed variant scores for AB-NAM lines, follow instructions in the comments section of the WBIP384_ABNAM_2012 genotyping experiment. 
Table 1. Summary of advanced backcross-nested association mapping trait values and heritabilities for multi-environment trait best linear unbiased predictors.

\begin{tabular}{|c|c|c|c|c|c|c|}
\hline Trait & Minimum & Maximum & Rasmusson & Mean & CV & Heritability \\
\hline Heading date (days after planting) & 44.24 & 61.62 & 50.69 & 51.26 & 4.62 & 0.82 \\
\hline Height $(\mathrm{cm})$ & 49.53 & 92.51 & 71.94 & 72.50 & 7.03 & 0.63 \\
\hline Test weight $\left(\mathrm{g} \mathrm{L}^{-1}\right)$ & 569.29 & 735.50 & 716.83 & 684.48 & 3.82 & 0.70 \\
\hline PTN† (tillers $0.5 \mathrm{~m}^{-1}$ ) & 53.56 & 63.71 & 59.09 & 58.66 & 2.75 & 0.11 \\
\hline Yield $\left(\mathrm{kg} \mathrm{ha}^{-1}\right)$ & 1799 & 5764 & 5283 & 4545 & 12.77 & 0.61 \\
\hline
\end{tabular}

†PTN, productive tiller number.
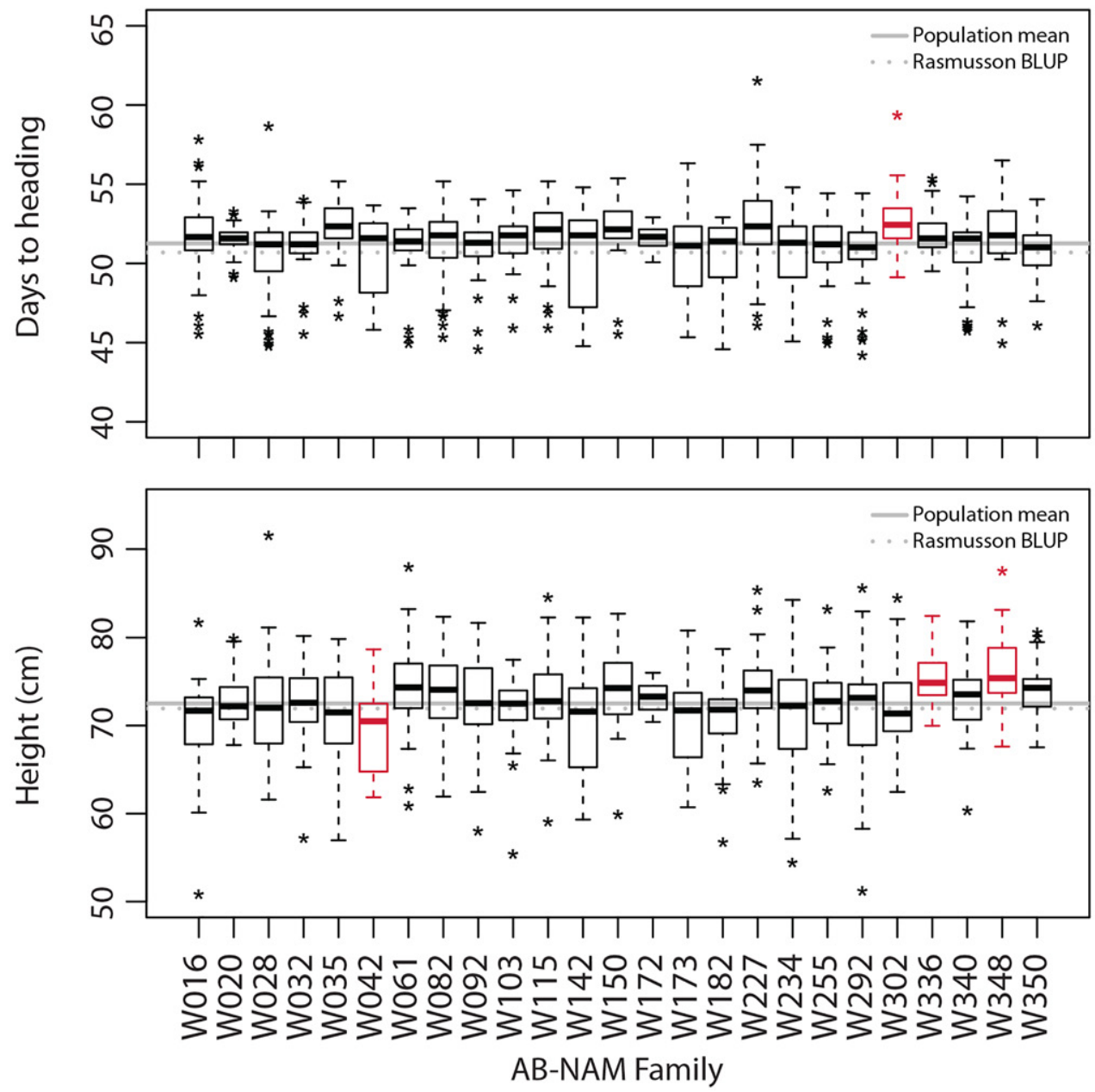

Fig. 1. (continued on next page) Box plots of multi-environment BLUP values for days to heading, height, test weight, tiller number, and yield split by advanced backcross-nested association mapping (AB-NAM) family. Population mean trait values are denoted by a solid horizontal gray line. Rasmusson trait values are denoted by a dashed horizontal gray line. Families with mean values that are significantly deviated from the population mean are shown in red.

\section{RESULTS AND DISCUSSION}

\section{Trait Variation, Heritability, and Correlations}

The wild barley AB-NAM exhibits a large amount of phenotypic and genotypic variation that may be useful for barley breeding (Nice et al., 2016). Here, we described the characterization of the AB-NAM for five agronomic traits of interest to spring six-row malting barley breeding programs. Days to heading, height, test weight, PTN, and yield were measured in two to five augmented field trials over 2 yr. Among these traits, all exhibited large ranges in phenotypic values, with the exception of PTN, which had a relatively narrow phenotypic range (Table 1 ).

Analysis of variance indicated significant $(p<0.0001)$ variation was explained by lines, and significant genotype $x$ environment interactions were observed when considering those individuals that were replicated within and across environments. Best linear unbiased predictors were calculated from multi-environment phenotypic data (Table 1). The distribution of phenotypic values subset by wild barley donor parent is shown in Fig. 1 and 

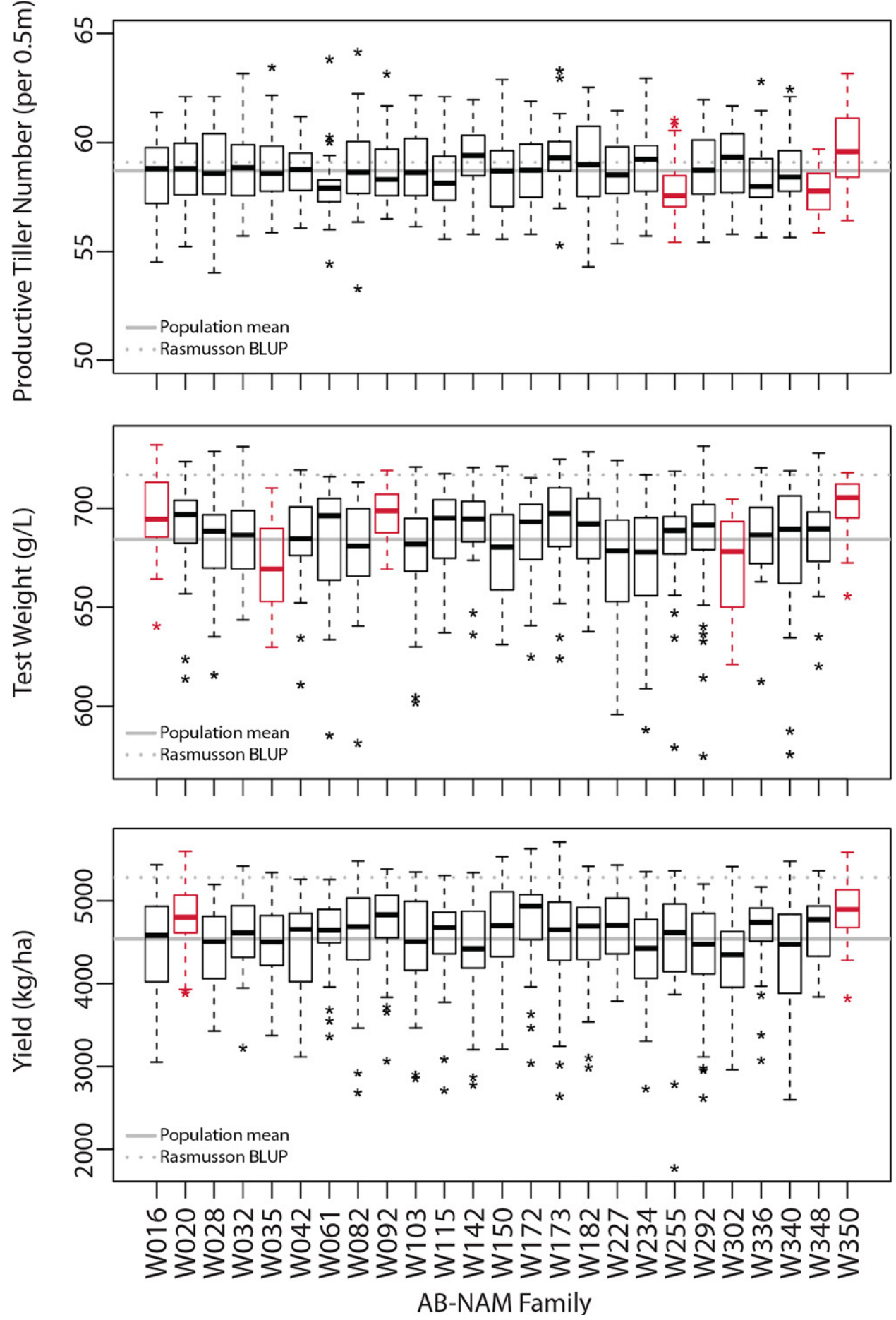

Fig. 1. Continued.

Supplemental Table S1. For days to heading, height, and PTN, the population means lie close to the value of Rasmusson. Whereas, for test weight and yield, the Rasmusson phenotype outperforms a large majority of the individuals in the population.

Estimates of trait heritability ranged from 0.11 to 0.82 (Table 1). Productive tiller number heritability was the lowest $\left(h^{2}=0.11\right)$, likely as a result of the relatively low variation $(\mathrm{CV}=2.75)$ and relatively high environmental and measurement error. The heritability of days to heading was high $\left(h^{2}=0.82\right)$, an observation that is consistent with other barley populations including the Halle Exotic Barley (HEB-25) wild barley derived NAM population (Maurer et al., 2015). Height, test weight, and yield each had intermediate heritability estimates that ranged from 0.61 to 0.70 (Table 1 ).

Heading date was significantly correlated with each of the other agronomic traits measured (Table 2). Heading date was most strongly, positively correlated with height, but it also had a moderate positive correlation with yield 
Table 2. Pearson correlations between traits.

\begin{tabular}{|c|c|c|c|c|c|}
\hline & $\begin{array}{c}\text { Heading } \\
\text { date }\end{array}$ & Height & $\begin{array}{c}\text { Test } \\
\text { weight }\end{array}$ & PTN† & Yield \\
\hline Heading date & - & - & - & - & - \\
\hline Height & $0.43^{\star \star \star}$ & & & & \\
\hline Test weight & $-0.16^{\star \star \star}$ & 0.00 & & & \\
\hline PTN & $-0.18^{\star \star \star}$ & $-0.32^{\star \star \star}$ & -0.01 & & \\
\hline Yield & $0.15^{\star \star \star}$ & $0.20^{\star \star \star}$ & $0.56^{\star \star \star}$ & 0.03 & \\
\hline
\end{tabular}

*** Significant at the 0.001 probability level.

† PTN, productive tiller number

and moderate negative correlations with test weight and PTN. In addition to the correlation with days to heading, height was negatively correlated with number of tillers and positively correlated with yield. Test weight was strongly, positively correlated with yield. Similar patterns of correlations were observed in the HEB-25 NAM population (Maurer et al., 2016).

\section{Distribution of Trait Values among Advanced Backcross-Nested Association Mapping Families}

Generally, the mean of individual families for each trait was similar to the mean of the full population (Fig. 1; Supplemental Table S1). For a few families, trait means deviated significantly $(p<0.01)$ from the population mean. The mean number of days to heading for the family derived from WBDC302 was significantly higher than the population-wide mean of $51.3 \mathrm{~d}$. The families derived from WBDC336 and WBDC348 were, on average, taller than the population mean, and the WBDC042 family mean was shorter than the population mean of 72.5 $\mathrm{cm}$. WBDC255 and WBDC348 had lower PTN, and WBDC350 had higher PTN than the population mean of 58.7 tillers per $0.5 \mathrm{~m}$. Test weights for families WBDC016, WBDC092, and WBDC350 were significantly higher than the population mean of $684 \mathrm{~g} \mathrm{~L}^{-1}$, and test weights for families WBDC035 and WBDC302 were lower than the population mean. WBDC020 and WBDC350 showed significantly higher yield. Among the families, WBDC350 performed quite well with regard to yield and test weight (Fig. 1). Individuals from 20 of the 25 families had yield BLUPs greater than or equal to Rasmusson and the highest-yielding, WBDC173-derived individual outyielded Rasmusson by $480 \mathrm{~kg} \mathrm{ha}^{-1}$ (Table 1).

\section{Mapping Complex Traits with the Advanced Backcross-Nested Association Mapping: Days to Heading}

A total of 10 loci were identified that exhibited significant associations with days to heading (Table 3). These loci were found on chromosomes $2 \mathrm{H}, 3 \mathrm{H}, 5 \mathrm{H}$, and $7 \mathrm{H}$ (Fig. 2). Loci on chromosome $2 \mathrm{H}$ and $7 \mathrm{H}$ were identified in all bootstrap samples and were the most highly significant loci identified for heading date (Table 3). The most significant variants were located on Morex sequence contig 94710, which contains the Ppd-H1 photoperiod sensitivity gene (Alqudah et al., 2014). In contrast to the photoperiod insensitive Rasmusson ppd-H1 allele, these photoperiod sensitive variants had an effect of reducing days to heading by $3.02 \mathrm{~d}$. While a majority of the variants in this region had a negative effect, some variants had a small positive effect of increasing the number of days to heading by 0.01 to $0.40 \mathrm{~d}$ (Supplemental Dataset S1). Three additional loci were identified on chromosome $2 \mathrm{H}$, with those at 41.22 and $85.98 \mathrm{cM}$ increasing the days to heading by 0.47 and $2.06 \mathrm{~d}$, respectively, and another locus on $2 \mathrm{H}$ exhibited both negative and positive effects with the positions of highest significance at 53.82 and $59.70 \mathrm{cM}$ (Table 3).

Loci on chromosome $3 \mathrm{H}$ at $51.77 \mathrm{cM}$ and $5 \mathrm{H}$ at positions 42.15, 113.89, and $119.24 \mathrm{cM}$ exhibited positive effects of 0.14 to $1.43 \mathrm{~d}$ in 8 to $45 \%$ of the bootstrap samples. An infrequently detected association was identified at $13.60 \mathrm{cM}$ on chromosome $7 \mathrm{H}$ with an effect of reducing days to heading by $0.37 \mathrm{~d}$. The other $7 \mathrm{H}$ locus contained variants of both positive and negative effects. Located at $29.96 \mathrm{cM}$, the variants with the highest significance in the region had an effect of increasing days to heading by 2.10 $\mathrm{d}$, while the other variants in the region, at $34.21 \mathrm{cM}$, had an effect of decreasing days to heading by $0.68 \mathrm{~d}$.

The genetic control of heading date in barley has been studied extensively (e.g., Cockram et al., 2007; Alqudah et al., 2014; Maurer et al., 2015). Maurer et al. (2015) examined heading date in a similar population to the wild barley AB-NAM. The Halle Exotic Barley (HEB-25) population is composed of 25 wild barley accessions backcrossed to a single cultivated barley. In their examination of heading date, they found a very wide phenotypic range of almost $50 \mathrm{~d}$, whereas, here we observed a more modest range of $\sim 17 \mathrm{~d}$ (Table 1). This difference likely is due to the additional backcross generation included in the development of the $\mathrm{BC}_{2}$-derived $\mathrm{AB}-\mathrm{NAM}$ population, which creates a more uniform genetic background than in the $\mathrm{BC}_{1}$-derived HEB-25 lines.

Consistent with results found here, the largest-effect association identified with the HEB-25 population was the Ppd-H1 locus on chromosome $2 \mathrm{H}$, which was also shown to be influential throughout barley development (Maurer et al., 2015, 2016). Besides Ppd-H1, other QTL corresponded to those identified in the HEB-25 population. The HvCEN locus (Comadran et al., 2012) on chromosome $2 \mathrm{H}$ at $58.00 \mathrm{cM}$, the $\mathrm{Vrn}-\mathrm{H} 1$ locus (Yan et al., 2003) on chromosome $5 \mathrm{H}$ at $125.76 \mathrm{cM}$, and the $\mathrm{Vrn}-\mathrm{H} 3$ locus (Yan et al., 2006) on chromosome $7 \mathrm{H}$ at 34.43 cM were identified in both studies (POPSEQ map positions per Alqudah et al., 2014). For Ppd-H1, HvCEN, and $V r n-H 3$, we identified variants in each region with both 
Table 3. Summary of marker-trait associations. Markers reported here are the marker with the highest average -log( $p)$ value among 100 bootstrap iterations for each quantitative trait loci (QTL). When markers at a single QTL had both positive and negative marker effects, the most significant marker was reported for each effect direction. All significant marker-trait associations can be found in Supplemental Dataset S1.

\begin{tabular}{|c|c|c|c|c|c|c|c|c|c|}
\hline Trait & Locus† & Variant $\ddagger$ & $\begin{array}{l}\text { Chromo- } \\
\text { some§ }\end{array}$ & $\mathrm{cM} \S$ & MAFף & FREQ\# & $-\log (p) \dagger \dagger$ & Effectł‡ & Ras§§ \\
\hline \multirow[t]{13}{*}{ Days to heading } & $2 \mathrm{H} .1$ & morex_contig_61987:8917_A/G & $2 \mathrm{H}$ & 19.05 & 0.02 & 1.00 & 7.29 & 0.01 & A \\
\hline & $2 \mathrm{H} .1$ & morex_contig_94710:1754_T/C* & $2 \mathrm{H}$ & 19.90 & 0.11 & 1.00 & 71.73 & -3.02 & $\mathrm{~T}$ \\
\hline & $2 \mathrm{H} .2$ & morex_contig_135313:5170_G/A & $2 \mathrm{H}$ & 41.22 & 0.01 & 0.39 & 4.28 & 0.47 & G \\
\hline & $2 \mathrm{H} .3$ & morex_contig_39365:4995_G/A & $2 \mathrm{H}$ & 53.82 & 0.02 & 0.07 & 3.91 & -1.16 & G \\
\hline & $2 \mathrm{H} .3$ & morex_contig_135238:1265_G/T & $2 \mathrm{H}$ & 59.70 & 0.04 & 0.08 & 4.13 & 0.47 & G \\
\hline & $2 \mathrm{H} .4$ & morex_contig_1565994:1482_TG/T & $2 \mathrm{H}$ & 85.98 & 0.01 & 0.12 & 4.18 & 2.06 & $\mathrm{~T}$ \\
\hline & 3H.1 & morex_contig_1578959:209_TC/T & $3 \mathrm{H}$ & 51.77 & 0.01 & 0.08 & 4.10 & 0.14 & $\mathrm{TC}$ \\
\hline & $5 \mathrm{H} .1$ & morex_contig_1595050:226_GTA/G* & $5 \mathrm{H}$ & 42.15 & 0.02 & 0.11 & 3.87 & 1.21 & GTA \\
\hline & $5 \mathrm{H} .2$ & morex_contig_2553463:241_GC/G* & $5 \mathrm{H}$ & 113.89 & 0.01 & 0.09 & 4.16 & 1.43 & GC \\
\hline & $5 \mathrm{H} .3$ & morex_contig_1560492:6299_T/C & $5 \mathrm{H}$ & 119.24 & 0.03 & 0.45 & 4.44 & 1.26 & $\mathrm{~T}$ \\
\hline & $7 \mathrm{H} .1$ & morex_contig_43906:1474_G/A & $7 \mathrm{H}$ & 13.60 & 0.02 & 0.08 & 3.85 & -0.37 & G \\
\hline & $7 \mathrm{H} .2$ & morex_contig_9006:1415_G/C** & $7 \mathrm{H}$ & 29.96 & 0.02 & 1.00 & 7.96 & 2.10 & G \\
\hline & $7 \mathrm{H} .2$ & morex_contig_1561657:2925_G/A* & $7 \mathrm{H}$ & 34.21 & 0.07 & 1.00 & 6.60 & -0.68 & G \\
\hline \multirow{20}{*}{$\begin{array}{l}\text { Height } \\
(\mathrm{cm})\end{array}$} & $1 \mathrm{H} .1$ & morex_contig_38760:17841_C/T* & $1 \mathrm{H}$ & 21.25 & 0.02 & 0.09 & 4.41 & -2.12 & $\mathrm{C}$ \\
\hline & $1 \mathrm{H} .2$ & morex_contig_42099:3456_G/A & $1 \mathrm{H}$ & 42.78 & 0.01 & 0.08 & 4.77 & -2.62 & G \\
\hline & $1 \mathrm{H} .3$ & morex_contig_6883:3404_A/G & $1 \mathrm{H}$ & 70.54 & 0.01 & 0.15 & 4.47 & -2.97 & A \\
\hline & $1 \mathrm{H} .3$ & $\begin{array}{c}\text { morex_contig_139934:324_ } \\
\text { ATGAACTTGGCTAG/A }\end{array}$ & $1 \mathrm{H}$ & 70.72 & 0.01 & 0.15 & 4.47 & -2.96 & ATGAA... \\
\hline & $1 \mathrm{H} .4$ & morex_contig_158638:4096_G/A* & $1 \mathrm{H}$ & 126.06 & 0.02 & 0.07 & 4.46 & -2.91 & G \\
\hline & $2 \mathrm{H} .1$ & morex_contig_94710:1754_T/C* & $2 \mathrm{H}$ & 19.90 & 0.11 & 1.00 & 27.84 & -4.63 & $\mathrm{~T}$ \\
\hline & $2 \mathrm{H} .2$ & morex_contig_2547325:563_C/G & $2 \mathrm{H}$ & 33.68 & 0.08 & 0.06 & 4.49 & -3.66 & $\mathrm{C}$ \\
\hline & $2 \mathrm{H} .3$ & morex_contig_2106916:1709_C/A & $2 \mathrm{H}$ & 40.37 & 0.01 & 0.56 & 5.44 & -3.77 & $\mathrm{C}$ \\
\hline & $2 \mathrm{H} .4$ & morex_contig_6288:2299_T/C* & $2 \mathrm{H}$ & 123.65 & 0.02 & 0.06 & 4.26 & -2.38 & $\mathrm{~T}$ \\
\hline & 3H.1 & morex_contig_39909:12902_A/C & $3 \mathrm{H}$ & 68.13 & 0.01 & 0.08 & 4.16 & -1.85 & A \\
\hline & $3 \mathrm{H} .2$ & morex_contig_40861:9707_C/T** & $3 \mathrm{H}$ & 108.85 & 0.13 & 1.00 & 6.55 & 2.52 & $\mathrm{C}$ \\
\hline & $4 \mathrm{H} .1$ & morex_contig_98608:1030_T/C & $4 \mathrm{H}$ & 22.24 & 0.04 & 0.50 & 4.52 & 2.61 & $\mathrm{~T}$ \\
\hline & $4 \mathrm{H} .2$ & morex_contig_1581403:1626_C/G & $4 \mathrm{H}$ & 43.48 & 0.01 & 0.07 & 4.19 & -1.89 & C \\
\hline & $4 \mathrm{H} .3$ & morex_contig_1569145:1199_G/T & $4 \mathrm{H}$ & 114.94 & 0.03 & 0.92 & 5.53 & -2.35 & G \\
\hline & $5 \mathrm{H} .1$ & morex_contig_54778:1059_G/A & $5 \mathrm{H}$ & 59.72 & 0.02 & 0.25 & 4.24 & -2.49 & G \\
\hline & $7 \mathrm{H} .1$ & morex_contig_1568403:2016_A/G & $7 \mathrm{H}$ & 20.96 & 0.04 & 0.14 & 4.17 & 2.37 & G \\
\hline & $7 \mathrm{H} .2$ & morex_contig_2547812:2781_A/T & $7 \mathrm{H}$ & 29.96 & 0.07 & 0.22 & 4.38 & 2.51 & $\mathrm{~T}$ \\
\hline & $7 \mathrm{H} .3$ & morex_contig_1579633:859_G/C & $7 \mathrm{H}$ & 42.28 & 0.02 & 0.06 & 4.50 & -1.72 & G \\
\hline & $7 \mathrm{H} .4$ & morex_contig_323672:471_C/T* & $7 \mathrm{H}$ & 48.16 & 0.03 & 0.40 & 4.59 & -1.34 & $\mathrm{C}$ \\
\hline & $7 \mathrm{H} .5$ & morex_contig_42961:5037_C/T* & $7 \mathrm{H}$ & 133.92 & 0.02 & 0.06 & 4.27 & -1.48 & $\mathrm{C}$ \\
\hline \multirow{11}{*}{$\begin{array}{l}\text { Test weight } \\
\left(g L^{-1}\right)\end{array}$} & $1 \mathrm{H} .1$ & morex_contig_166809:1737_A/T & $1 \mathrm{H}$ & 94.90 & 0.11 & 1.00 & 10.55 & -20.66 & A \\
\hline & $1 \mathrm{H} .1$ & morex_contig_1561363:4513_C/G & $1 \mathrm{H}$ & 97.73 & 0.03 & 1.00 & 8.18 & 4.25 & C \\
\hline & $2 \mathrm{H} .1$ & morex_contig_381927:297_A/C & $2 \mathrm{H}$ & 52.62 & 0.02 & 0.38 & 4.68 & -17.19 & A \\
\hline & $2 \mathrm{H} .2$ & morex_contig_47818:3505_C/T & $2 \mathrm{H}$ & 59.42 & 0.03 & 0.77 & 5.22 & -16.49 & $\mathrm{C}$ \\
\hline & $3 \mathrm{H} .1$ & morex_contig_45244:1965_G/GA & $3 \mathrm{H}$ & 43.13 & 0.03 & 0.31 & 4.51 & -10.26 & G \\
\hline & 3H.1 & morex_contig_5708:4611_C/T* & $3 \mathrm{H}$ & 45.82 & 0.04 & 0.07 & 4.32 & 2.22 & C \\
\hline & $5 \mathrm{H} .1$ & morex_contig_41843:6990_C/T & $5 \mathrm{H}$ & 0.14 & 0.03 & 0.51 & 4.50 & -14.32 & $\mathrm{C}$ \\
\hline & $5 \mathrm{H} .2$ & morex_contig_8004:481_T/C & $5 \mathrm{H}$ & 80.49 & 0.01 & 0.09 & 4.44 & -43.64 & $\mathrm{~T}$ \\
\hline & $5 \mathrm{H} .3$ & morex_contig_138324:6222_T/C & $5 \mathrm{H}$ & 107.57 & 0.02 & 0.11 & 4.44 & -20.43 & $\mathrm{~T}$ \\
\hline & $7 \mathrm{H} .1$ & morex_contig_79300:514_C/A* & $7 \mathrm{H}$ & 41.43 & 0.02 & 0.50 & 4.77 & -22.82 & C \\
\hline & $7 \mathrm{H} .2$ & morex_contig_52768:4574_C/A & $7 \mathrm{H}$ & 61.19 & 0.02 & 0.36 & 4.54 & -23.88 & C \\
\hline \multirow{2}{*}{$\begin{array}{l}\text { Productive tiller } \\
\text { no. (per } 0.5 \mathrm{~m} \text { ) }\end{array}$} & $2 \mathrm{H} .1$ & morex_contig_94710:4178_G/A & $2 \mathrm{H}$ & 19.90 & 0.10 & 0.24 & 6.65 & 0.65 & G \\
\hline & $4 \mathrm{H} .1$ & morex_contig_1562579:4864_G/C & $4 \mathrm{H}$ & 91.29 & 0.03 & 0.10 & 6.29 & 1.04 & G \\
\hline
\end{tabular}

(cont'd.)

positive and negative effects. Loci found in the HEB-25 population, but not found in the AB-NAM population included denso (Jia et al., 2009) on chromosome $3 \mathrm{H}$, a novel locus on chromosome $4 \mathrm{H}$, and $\mathrm{Vrn}-\mathrm{H} 2$ (Yan et al., 2004) on chromosome 4H. In addition to the loci already mentioned, we identified loci that colocalize with $\mathrm{H} v \mathrm{CO} 18$ on chromosome $2 \mathrm{H}$ at $41.85 \mathrm{cM}, \mathrm{H} v \mathrm{CO} 3$ on chromosome $5 \mathrm{H}$ at $43.76 \mathrm{cM}$, and three novel QTL on 
Table 3. Continued.

\begin{tabular}{|c|c|c|c|c|c|c|c|c|c|}
\hline Trait & Locus† & Variantł & $\begin{array}{c}\text { Chromo- } \\
\text { some§ }\end{array}$ & cM§ & MAFף & FREQ\# & $-\log (p) \dagger \dagger$ & Effectł‡ & Ras§§ \\
\hline \multirow{11}{*}{$\begin{array}{l}\text { Yield } \\
\left(\mathrm{kg} \mathrm{ha}^{-1}\right)\end{array}$} & $1 \mathrm{H} .1$ & morex_contig_166809:1737_A/T & $1 \mathrm{H}$ & 94.90 & 0.11 & 0.52 & 4.31 & -327 & $A$ \\
\hline & $2 \mathrm{H} .1$ & morex_contig_56215:381_T/C* & $2 \mathrm{H}$ & 19.48 & 0.11 & 0.98 & 5.56 & -288 & $\mathrm{~T}$ \\
\hline & $3 \mathrm{H} .1$ & morex_contig_158632:4370_A/G & $3 \mathrm{H}$ & 44.83 & 0.10 & 1.00 & 19.25 & -590 & A \\
\hline & $3 \mathrm{H} .2$ & morex_contig_2557470:544_T/C & $3 \mathrm{H}$ & 57.08 & 0.03 & 0.06 & 4.09 & 169 & $\mathrm{~T}$ \\
\hline & $3 \mathrm{H} .3$ & morex_contig_64931:1051_G/A & $3 \mathrm{H}$ & 76.35 & 0.06 & 0.07 & 4.32 & -335 & G \\
\hline & $3 \mathrm{H} .4$ & morex_contig_358142:901_C/T & $3 \mathrm{H}$ & 86.33 & 0.01 & 0.06 & 3.97 & -281 & C \\
\hline & $5 \mathrm{H} .1$ & morex_contig_54820:6729_T/A & $5 \mathrm{H}$ & 13.26 & 0.04 & 0.06 & 4.26 & -224 & $\mathrm{~T}$ \\
\hline & $5 \mathrm{H} .2$ & morex_contig_135266:2648_T/C** & $5 \mathrm{H}$ & 47.50 & 0.02 & 0.89 & 5.14 & -361 & $\mathrm{~T}$ \\
\hline & $6 \mathrm{H} .1$ & morex_contig_37935:10308_C/A & $6 \mathrm{H}$ & 113.21 & 0.01 & 0.08 & 4.60 & -412 & C \\
\hline & $6 \mathrm{H} .2$ & morex_contig_2546718:7710_A/G* & $6 \mathrm{H}$ & 126.49 & 0.02 & 0.16 & 4.60 & -404 & A \\
\hline & $7 \mathrm{H} .1$ & morex_contig_37512:13958_A/G & $7 \mathrm{H}$ & 140.65 & 0.02 & 0.08 & 4.05 & -302 & A \\
\hline
\end{tabular}

† QTL on the same chromosome were considered unique loci if there was a >5 cM gap between significant markers.

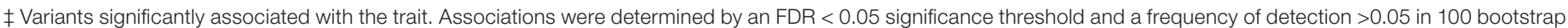

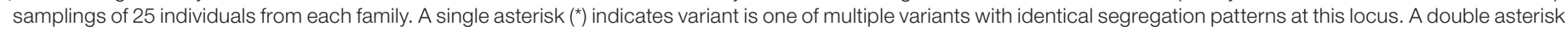
$\left(^{\star *}\right)$ indicates variant is one of multiple variants with identical segregation patterns at this locus, some of which are found on different contigs.

$\S$ Chromosome and cM positions of Morex contig contain the variant as determined by the Mascher et al. (2013a) POPSEQ map.

I MAF, minor allele frequency of variant in the AB-NAM population.

\# FREQ, frequency of significant association with variant detected in 100 bootstrap samples.

††-log( $p$-value) averaged across significant bootstrap tests.

掞 Relative effect of non-Rasmusson allele averaged across significant bootstrap tests.

$\S \S$ Ras, Rasmusson allele at variant locus.

chromosomes $2 \mathrm{H}, 5 \mathrm{H}$, and $7 \mathrm{H}$ (Supplemental Dataset S1; Alqudah et al., 2014). The results and genetic materials described here provide a resource for developing cultivars with varying times to heading.

\section{Mapping Complex Traits with the Advanced Backcross-Nested Association Mapping: Height}

The largest number of QTL (19) were identified for height, several of which appear to correspond to QTL identified in previous mapping experiments (as queried in Grain Genes: http://wheat.pw.usda.gov/). These loci were found on all chromosomes except $6 \mathrm{H}$ (Fig. 2) and exhibited effects that ranged from -4.63 to $2.61 \mathrm{~cm}$ (Supplemental Dataset S1). The most consistently identified loci were found in all bootstrap samples and located on chromosome $2 \mathrm{H}$ at $19.90 \mathrm{cM}$ and on $3 \mathrm{H}$ at $108.85 \mathrm{cM}$. The $2 \mathrm{H}$ association produced the largest effect of -4.63 $\mathrm{cm}$ and corresponds to the same $P p d-H 1$ variants that are strongly associated with heading date. The locus on chromosome $7 \mathrm{H}$ at $29.96 \mathrm{cM}$ was also coincident with a days to heading locus. In this case, the most significant variants and contigs were not the same for the heading date and height loci, although the contigs in which they were identified are mapped to the same location (Supplemental Dataset S1). The locus with the second highest significance, located on $3 \mathrm{H}$ at $108.85 \mathrm{cM}$, colocalizes with the semidwarf gene denso (Jia et al., 2009). Although denso has been previously associated with heading date, here we only found significant associations with height. In addition to associations with Ppd-H1 and denso, several of the height QTL identified in the AB-NAM were also identified in the HEB-25 population (Maurer et al., 2016). In their examination of developmental stages of barley, Maurer et al. (2016) found QTL for both developmental characteristics and height at locations coincident with flowering time-related genes HvELF3 and HvCEN and with vernalization genes $\mathrm{Vrn}-\mathrm{H} 2$ and $\mathrm{Vrn}-\mathrm{H} 3$. A coincident height QTL for each of these was also identified in the AB-NAM with the exception of HvCEN.

\section{Mapping Complex Traits with the Advanced Backcross-Nested Association Mapping: Productive Tiller Number}

The heritability of PTN in this study was low $\left(h^{2}=0.11\right)$ because of a combination of small variation and high measurement error. In the field, variability in seeding and germination may have contributed to high measurement error. The photoperiod-sensitive, non-Rasmusson alleles for variants in the $P p d-H 1$ gene were identified as having an effect of increasing number of tillers by 0.65 , and a novel QTL on chromosome $4 \mathrm{H}$ at $91.29 \mathrm{cM}$ increased number of tillers by 1.04 (Fig. 2). Neither locus was identified in a large proportion of bootstrap samplings (Table 3). Alqudah et al. (2016) identified photoperiod sensitivity (Ppd-H1) and row type (Vrs1) as major determinants of tiller variation throughout cultivated and landrace spring barley developmental stages. They observed significant positive effect of photoperiod insensitivity ( $p p d-H 1)$ for all stages of tiller development, but the effect was the smallest when measuring tillers at the productive harvest stage. Limited differentiation at the productive tillering stage and a fixed 

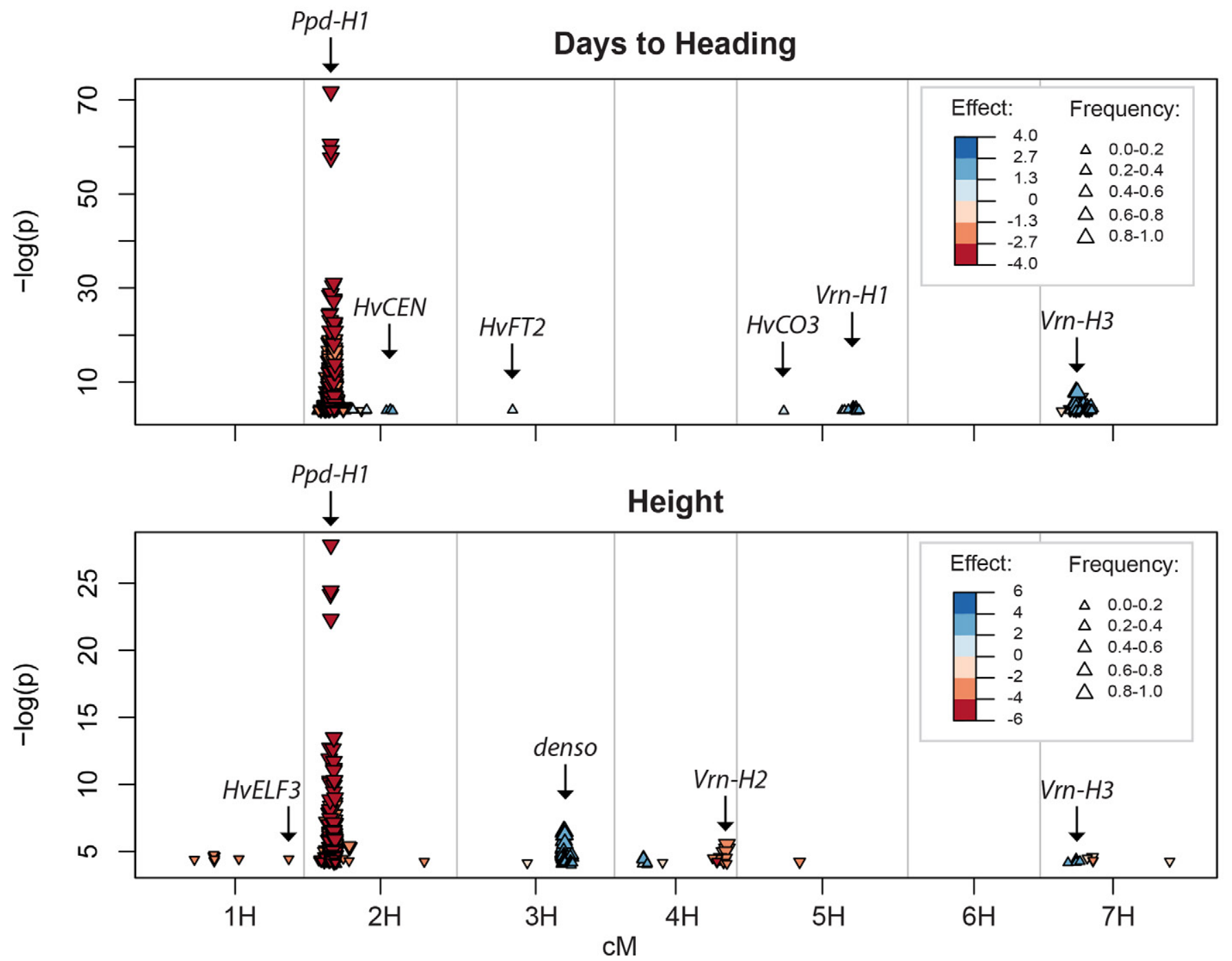

Fig. 2. Significant marker-trait associations. Associations shown are those detected above a false discovery rate equal to 0.05 threshold in $>5 \%$ of 100 bootstrap samplings of 25 individuals per advanced backcross-nested association mapping family. Triangles pointing up indicate a positive effect of the non-Rasmusson allele. Triangles pointing down indicate a negative effect of the non-Rasmusson allele. Color indicates the magnitude of effects. Size of the triangle indicates the frequency of detection among bootstrap samples.

six-rowed type in the AB-NAM are likely contributing to the limited variation seen in the AB-NAM population. The QTL identified on $4 \mathrm{H}$ at $91.29 \mathrm{cM}$ corresponds to a QTL identified by Alqudah et al. (2016) for productive tiller number, which they attributed to the SUCROSE TRANSPORTER 1 (HvSUT1) gene in the region.

\section{Mapping Complex Traits with the Advanced Backcross-Nested Association Mapping: Test Weight}

Test weight is a volumetric measurement that is influenced by seed shape and size. Test weight was mapped to nine loci found on chromosomes $1 \mathrm{H}, 2 \mathrm{H}, 3 \mathrm{H}, 5 \mathrm{H}$, and $7 \mathrm{H}$ (Fig. 2). The $1 \mathrm{H}$ locus at $94.90 \mathrm{cM}$ was the most consistently identified locus with an effect of decreasing the test weight by $20.66 \mathrm{~g} \mathrm{~L}^{-1}$. This locus corresponds to the thresh-1 locus that was previously fine mapped using a wild barley introgression population (Schmalenbach et al., 2011). The poor threshability exhibited by some AB-NAM lines has a major impact on test weight because the presence of awns after threshing affects packability of the grain. A few positive effect variants were identified in this region at $97.73 \mathrm{cM}$ (Supplemental Dataset S1). A majority of the other loci identified produced a negative effect with the exception of the locus at 43.11 and 45.82 $\mathrm{cM}$ on chromosome $3 \mathrm{H}$, which contained variants with both positive and negative effects.

\section{Mapping Complex Traits with the Advanced Backcross-Nested Association Mapping: Yield}

Eleven significant marker-trait associations for yield were identified across all chromosomes except $4 \mathrm{H}$ (Fig. 2). Only a single, infrequently identified locus on $3 \mathrm{H}$ at 57.08 cM exhibited positive effects of the non-Rasmusson allele (Supplemental Dataset S1). The significant associations 
for yield overlapped with those for other traits. The locus on chromosome $1 \mathrm{H}$ at 94.90 was shared with test weight along with the most commonly identified locus on $3 \mathrm{H}$ at $44.83 \mathrm{cM}$. These are likely related to the poor threshability and brittle rachis morphology of wild barley, respectively. The brittle rachis provides a means for dispersal of seeds. Because seed dispersal is disadvantageous for cultivated agriculture, a nonshattering spike was one of the primary domestication traits (Pourkheirandish and Komatsuda, 2007). During the process of developing the AB-NAM population, we did not impose selection against seed shattering. Therefore, it is not surprising that the brittle rachis complex on chromosome $3 \mathrm{H}$ (Komatsuda et al., 2004) is the most influential yield QTL identified. A QTL for yield was also identified on chromosome $2 \mathrm{H}$, with significant associations to variants on the contig containing $P p d-H 1$, a major contributor to heading date, height, and tiller count (Supplemental Dataset S1).

\section{Relationships among Traits}

Correlations between traits were common, and heading date was significantly correlated with each of the other traits: height, test weight, tiller count, and yield (Table 2). This phenotypic correlation is reflected in the overlap of the large effect QTL for heading date, height, PTN, and yield localized to variants in the Ppd-H1 gene on Morex contig 94710 (Table 3; Supplemental Dataset S1). For each trait except test weight, these variants had highly significant and frequently identified associations. This reflects the importance of $\mathrm{Ppd}-\mathrm{H} 1$ in regulating plant growth and must be considered when working with germplasm that contains various alleles at this locus. While this major effect QTL was shared between several traits, relatively few of the smaller-effect loci were shared among traits. Furthermore, all traits except PTN had both positive and negative significant marker-trait associations, and at one or more loci for each trait, variants exhibited both positive and negative effects (Table 3), suggesting the presence of multiple non-Rasmusson haplotypes in the population.

\section{CONCLUSIONS}

We grew the phenotypically and genetically diverse wild barley AB-NAM in field trials in 2012 and 2013 in Minnesota, North Dakota, and Montana. The AB-NAM design allowed for screening in standard field trials, minimizing the unadapted traits present in the wild barley parental accessions, while maintaining large amounts of diversity. We identified several QTL for each trait measured. In each case, both previously identified and novel QTL were found. Transgressive segregation for test weight and yield is minimal, but there were some lines that had higher test weight and yield than Rasmusson. The AB-NAM population is a resource available for screening large amounts of genetic diversity in a genetic background that is adapted to the Upper Midwest region of the United States.

\section{Supplemental Information Available}

Supplemental information is available with the online version of this manuscript.

\section{Conflict of Interest Disclosure}

The authors have no conflicts of interest to declare.

\section{Acknowledgments}

Funding was provided by the Triticeae Coordinated Agricultural Project (USDA-NIFA, 2011-68002-30029), and by a USDA National Needs Fellowship (USDA-NIFA, 200738420-17749). We wish to thank Ed Schiefelbein, Guillermo Valesquez, and Martin Hochhalter for field management, and Shane Heinen for greenhouse support.

\section{References}

Alqudah, A.M., R. Koppolu, G.M. Wolde, A. Graner, and T. Schnurbusch. 2016. The genetic architecture of barley plant stature. Front. Genet. doi:10.3389/fgene.2016.00117

Alqudah, A.M., R. Sharma, R.K. Pasam, A. Graner, B. Kilian, and T. Schnurbusch. 2014. Genetic dissection of photoperiod response based on GWAS of pre-anthesis phase duration in spring barley. PLoS One 9:e113120. doi:10.1371/journal.pone.0113120

Butler, D.G., B.R. Cullis, A.R. Gilmour, and B.J. Gogel. 2009. ASReml-R Reference Manual Release 3.0, VSN International Ltd, Hemel Hempstead, UK.

Churchill, G.A., D.C. Airey, H. Allayee, J.M. Angel, A.D. Attie, J. Beatty, et al. 2004. The Collaborative Cross, a community resource for the genetic analysis of complex traits. Nat. Genet. 36:1133-1137. doi:10.1038/ng1104-1133

Cockram, J., H. Jones, F.J. Leigh, D. O’Sullivan, W. Powell, D.A. Laurie, and A.J. Greenland. 2007. Control of flowering time in temperate cereals: Genes, domestication, and sustainable productivity. J. Exp. Bot. 58:1231-1244. doi:10.1093/jxb/erm042

Comadran, J., B. Kilian, J. Russell, L. Ramsay, N. Stein, M. Ganal, et al. 2012. Natural variation in a homolog of Antirrhinum CENTRORADIALIS contributed to spring growth habit and environmental adaptation in cultivated barley. Nat. Genet. 44:1388-1392. doi:10.1038/ng.2447

Condón, F., C. Gustus, D.C. Rasmusson, and K.P. Smith. 2008. Effect of advanced cycle breeding on genetic diversity in barley breeding germplasm. Crop Sci. 48:1027-1036. doi:10.2135/cropsci2007.07.0415

Ellis, R.P., B.P. Forster, D. Robinson, L.L. Handley, D.C. Gordon, J.R. Russell, and W. Powell. 2000. Wild barley: A source of genes for crop improvement in the 21st century? J. Exp. Bot. 51:9-17. doi:10.1093/jexbot/51.342.9

Endelman, J.B. 2011. Ridge regression and other kernels for genomic selection with $\mathrm{R}$ package rrBLUP. Plant Genome 4:250. doi:10.3835/plantgenome2011.08.0024

Eshghi, R., S. Salayeva, F. Ebrahimpour, M. Rahimi, M. Baraty, and J. Ojaghi. 2013. Advanced-backcross QTL analysis in hulless 
barley: I. Detection of exotic alleles for yield and yield components introgressed from Hordeum vulgare ssp. spontaneum. Int. J. Agric. Crop Sci. 5:95-100.

Fischbeck, G. 2003. Diversification through breeding. In: R. von Bothmer, T. van Hintum, H. Knüpffer, and K. Sato, editors, Developments in plant genetics and breeding. Elsevier Science, Amsterdam, Netherlands. p. 29-52

Fu, Y.B., and D.J. Somers. 2009. Genome-wide reduction of genetic diversity in wheat breeding. Crop Sci. 49:161-168. doi:10.2135/ cropsci2008.03.0125

Gyenis, L., S.J. Yun, K.P. Smith, B.J. Steffenson, E. Bossolini, M.C. Sanguineti, and G.J. Muehlbauer. 2007. Genetic architecture of quantitative trait loci associated with morphological and agronomic trait differences in a wild by cultivated barley cross. Genome 50:714-723. doi:10.1139/G07-054

Hajjar, R., and T. Hodgkin. 2007. The use of wild relatives in crop improvement: A survey of developments over the last 20 years. Euphytica 156:1-13. doi:10.1007/s10681-007-9363-0

Hoffmann, A., A. Maurer, and K. Pillen. 2012. Detection of nitrogen deficiency QTL in juvenile wild barley introgression lines growing in a hydroponic system. BMC Genet. 13:88. doi:10.1186/1471-2156-13-88

Huang, X., M.J. Paulo, M. Boer, S. Effgen, P. Keizer, M. Koornneef, and F.A. van Eeuwijk. 2011. Analysis of natural allelic variation in Arabidopsis using a multiparent recombinant inbred line population. Proc. Natl. Acad. Sci. USA 108:4488-4493. doi:10.1073/pnas.1100465108

Jia, Q., J. Zhang, S. Westcott, X.Q. Zhang, M. Bellgard, and R. Lance, C. Li. 2009. GA-20 oxidase as a candidate for the semidwarf gene sdw1/denso in barley. Funct. Integr. Genomics 9:255262. doi:10.1007/s10142-009-0120-4

Kalladan, R., S. Worch, H. Rolletschek, V. T. Harshavardhan, L. Kuntze, C. Seiler, N. Sreenivasulu, and M.S. Röder. 2013. Identification of quantitative trait loci contributing to yield and seed quality parameters under terminal drought in barley advanced backcross lines. Mol. Breed. 32:71-90. doi:10.1007/s11032-013-9853-9

Kang, H.M., J.H. Sul, S.K. Service, N.A. Zaitlen, S.Y. Kong, N.B. Freimer, et al. 2010. Variance component model to account for sample structure in genome-wide association studies. Nat. Genet. 42:348-354. doi:10.1038/ng.548

King, E.G., C.M. Merkes, C.L. McNeil, S.R. Hoofer, S. Sen, K.W. Broman, et al. 2012. Genetic dissection of a model complex trait using the Drosophila Synthetic Population Resource. Genome Res. 22:1558-1566. doi:10.1101/gr.134031.111

Komatsuda, T., P. Maxim, N. Senthil, and Y. Mano. 2004. Highdensity AFLP map of nonbrittle rachis 1 (btr1) and 2 (btr2) genes in barley (Hordeum vulgare L.). Theor. Appl. Genet. 109:986-995. doi:10.1007/s00122-004-1710-0

Kover, P.X., W. Valdar, J. Trakalo, N. Scarcelli, I.M. Ehrenreich, M.D. Purugganan, et al. 2009. A multiparent advanced generation inter-cross to fine-map quantitative traits in Arabidopsis thaliana. PLoS Genet. 5:e1000551. doi:10.1371/journal.pgen.1000551

Li, J.Z., X.Q. Huang, F. Heinrichs, M.W. Ganal, and M.S. Röder. 2005. Analysis of QTLs for yield, yield components, and malting quality in a BC3-DH population of spring barley. Theor. Appl. Genet. 110:356-363. doi:10.1007/s00122-004-1847-x

Li, J.Z., X.Q. Huang, F. Heinrichs, M.W. Ganal, and M.S. Röder. 2006. Analysis of QTLs for yield components, agronomic traits, and disease resistance in an advanced backcross population of spring barley. Genome 49:454-466. doi:10.1139/G05-128

Lin, C.S., and G. Poushinsky. 1985. A modified augmented design (type 2) for rectangular plots. Can. J. Plant Sci. 65:743-749. doi:10.4141/cjps85-094

Mace, E.S., C.H. Hunt, and D.R. Jordan. 2013. Supermodels: Sorghum and maize provide mutual insight into the genetics of flowering time. Theor. Appl. Genet. 126:1377-1395. doi:10.1007/ s00122-013-2059-z

March, T.J., D. Richter, T. Colby, A. Harzen, J. Schmidt, and K. Pillen. 2012. Identification of proteins associated with malting quality in a subset of wild barley introgression lines. Proteomics 12:2843-2851. doi:10.1002/pmic.201200117

Mascher, M., G.J. Muehlbauer, D.S. Rokhsar, J. Chapman, J. Schmutz, K. Barry, et al. 2013a. Anchoring and ordering NGS contig assemblies by population sequencing (POPSEQ). Plant J. 76:718-727. doi:10.1111/tpj.12319

Mascher, M., T.A. Richmond, D.J. Gerhardt, A. Himmelbach, L. Clissold, D. Sampath, et al. 2013b. Barley whole exome capture: A tool for genomic research in the genus Hordeum and beyond. Plant J. 76:494-505. doi:10.1111/tpj.12294

Maurer, A., V. Draba, Y. Jiang, F. Schnaithmann, R. Sharma, E. Schumann, et al. 2015. Modelling the genetic architecture of flowering time control in barley through nested association mapping. BMC Genomics 16:290. doi:10.1186/s12864-015-1459-7

Maurer, A., V. Draba, and K. Pillen. 2016. Genomic dissection of plant development and its impact on thousand grain weight in barley through nested association mapping. J. Exp. Bot. 67:25072518. doi:10.1093/jxb/erw070

Mohammadi, M., T.K. Blake, A.D. Budde, S. Chao, P.M. Hayes, R.D. Horsley, et al. 2015. A genome-wide association study of malting quality across eight U.S. barley breeding programs. Theor. Appl. Genet. 128:705-721. doi:10.1007/s00122-015-2465-5

Morrell, P.L., E.S. Buckler, and J. Ross-Ibarra. 2012. Crop genomics: Advances and applications. Nat. Rev. Genet. 13:85-96. doi:10.1038/nrg3097

Muñoz-Amatriaín, M., A. Cuesta-Marcos, J.B. Endelman, J. Comadran, J.M. Bonman, H.E. Bockelman, et al. 2014. The USDA Barley Core Collection: Genetic diversity, population structure, and potential for genome-wide association studies. PLoS One 9:e94688. doi:10.1371/journal.pone.0094688

Muñoz-Amatriaín, M., Y. Xiong, M.R. Schmitt, H. Bilgic, A.D. Budde, S. Chao, et al. 2010. Transcriptome analysis of a barley breeding program examines gene expression diversity and reveals target genes for malting quality improvement. BMC Genomics 11:1-15. doi:10.1186/1471-2164-11-653

Myles, S., J. Peiffer, P.J. Brown, E.S. Ersoz, Z. Zhang, D.E. Costich, and E.S. Buckler. 2009. Association mapping: Critical considerations shift from genotyping to experimental design. Plant Cell 21:2194-2202. doi:10.1105/tpc.109.068437

Naz, A.A., M. Arifuzzaman, S. Muzammil, K. Pillen, and J. Léon. 2014. Wild barley introgression lines revealed novel QTL alleles for root and related shoot traits in the cultivated barley (Hordeum vulgare L.). BMC Genet. 15:107. doi:10.1186/s12863-014-0107-6

Nice, L.M., B.J. Steffenson, G.L. Brown-Guedira, E.D. Akhunov, C. Liu, T.J.Y. Kono, et al. 2016. Development and genetic characterization of an advanced backcross-nested association mapping $(A B-N A M)$ population of wild $\times$ cultivated barley. Genetics. doi:10.1534/genetics.116.190736

Pourkheirandish, M., and T. Komatsuda. 2007. The importance of barley genetics and domestication in a global perspective. Ann. Bot. (Lond.) 100:999-1008. doi:10.1093/aob/mcm139

Rasmusson, D.C., and R.L. Phillips. 1997. Plant breeding progress and genetic diversity from de novo variation and elevated 
epistasis. Crop Sci. 37:303-310. doi:10.2135/cropsci1997.001118 3X003700020001x

Rafalski, J.A. 2002. Novel genetic mapping tools in plants: SNPs and LD-based approaches. Plant Sci. 162:329-333. doi:10.1016/ S0168-9452(01)00587-8

Rostoks, N., L. Ramsay, K. MacKenzie, L. Cardle, P.R. Bhat, M.L. Roose, et al. 2006. Recent history of artificial outcrossing facilitates whole-genome association mapping in elite inbred crop varieties. Proc. Natl. Acad. Sci. USA 103:18656-18661. doi:10.1073/pnas.0606133103

Roy, J.K., K.P. Smith, G.J. Muehlbauer, et al. 2010. Association mapping of spot blotch resistance in wild barley. Mol. Breed. 26:243-256. doi:10.1007/s11032-010-9402-8

Russell, J., M. Mascher, I.K. Dawson, et al. 2016. Exome sequencing of geographically diverse barley landraces and wild relatives gives insights into environmental adaptation. Nat. Genet. 48:1024-1030. doi:10.1038/ng.3612

Saal, B., M. von Korff, J. Léon, and K. Pillen. 2011. Advancedbackcross QTL analysis in spring barley: IV. Localization of QTL $\times$ nitrogen interaction effects for yield-related traits. Euphytica 177:223-239. doi:10.1007/s10681-010-0252-6

Schmalenbach, I., T.J. March, T. Bringezu, R. Waugh, K. Pillen, and B.S. Gill. 2011. High-resolution genotyping of wild barley introgression lines and fine-mapping of the threshability locus thresh-1 using the Illumina GoldenGate Assay. G3: Genes, Genomes, Genet. 1:187-196. doi:10.1534/g3.111.000182

Schmalenbach, I., and K. Pillen. 2009. Detection and verification of malting quality QTLs using wild barley introgression lines. Theor. Appl. Genet. 118:1411-1427. doi:10.1007/s00122-009-0991-8

Schnaithmann, F., D. Kopahnke, and K. Pillen. 2014. A first step toward the development of a barley NAM population and its utilization to detect QTLs conferring leaf rust seedling resistance. Theor. Appl. Genet. 127:1513-1525. doi:10.1007/s00122-014-2315-x

Schnaithmann, F., and K. Pillen. 2013. Detection of exotic QTLs controlling nitrogen stress tolerance among wild barley introgression lines. Euphytica 189:67-88. doi:10.1007/s10681-012-0711-3

Smith, K.P., D.C. Rasmusson, E. Schiefelbein, J.J. Wiersma, J.V. Wiersma, A. Budde, et al. 2010. Registration of "Rasmusson" Barley. J. Plant Reg. 4:167-170. doi:10.3198/jpr2009.10.0622crc

Steffenson, B.J., P. Olivera, J.K. Roy, Y. Jin, K.P. Smith, and G.J. Muehlbauer. 2007. A walk on the wild side: Mining wild wheat and barley collections for rust resistance genes. Aust. J. Agric. Res. 58:532-544. doi:10.1071/AR07123

Stupar, R.M., and J.E. Specht. 2013. Insights from the soybean (Glycine max and Glycine soja) genome: Past, present, and future. In: D.L. Sparks, editor, Advances in agronomy. Academic Press, Cambridge, MA. p. 177-204.

Tanksley, S.D., and J.C. Nelson. 1996. Advanced backcross QTL analysis: A method for the simultaneous discovery and transfer of valuable QTLs from unadapted germplasm into elite breeding lines. Theor. Appl. Genet. 92:191-203. doi:10.1007/BF00223376

Technow, F. 2011. R package mvngGrAd: Moving grid adjustment in plant breeding field trials. $\mathrm{R}$ package version 0.1. Univ. of Hohenheim, Inst. of Plant Breeding, Seed Sci. and Population Genetics, Stuttgart, Germany

Von Korff, M., H. Wang, J. Léon, and K. Pillen. 2005. AB-QTL analysis in spring barley. I. Detection of resistance genes against powdery mildew, leaf rust and scald introgressed from wild barley. Theor. Appl. Genet. 111:583-590. doi:10.1007/s00122-005-2049-x

Von Korff, M., H. Wang, J. Léon, and K. Pillen. 2006. AB-QTL analysis in spring barley: II. Detection of favourable exotic alleles for agronomic traits introgressed from wild barley $(H$. vulgare ssp. spontaneum). Theor. Appl. Genet. 112:1221-1231. doi:10.1007/ s00122-006-0223-4

Von Korff, M., H. Wang, J. Léon, and K. Pillen. 2008. AB-QTL analysis in spring barley: III. Identification of exotic alleles for the improvement of malting quality in spring barley ( $H$. vulgare ssp. spontaneum). Mol. Breed. 21:81-93. doi:10.1007/s11032-007-9110-1

Wang, B., and P.W. Chee. 2010. Application of advanced backcross QTL analysis in crop improvement. J. Plant Breed. Crop Sci. 2:221-232.

Yan, L., D. Fu, C. Li, A. Blechl, G. Tranquilli, M. Bonafede, et al. 2006. The wheat and barley vernalization gene VRN3 is an orthologue of FT. Proc. Natl. Acad. Sci. USA 103:19581-19586. doi:10.1073/pnas.0607142103

Yan, L., A. Loukoianov, A. Blechl, G. Tranquilli, W. Ramakrishna, P. SanMiguel, et al. 2004. The wheat VRN2 gene is a flowering repressor down-regulated by vernalization. Science 303:16401644. doi:10.1126/science. 1094305

Yan, L., A. Loukoianov, G. Tranquilli, M. Helguera, T. Fahima, and J. Dubcovsky. 2003. Positional cloning of the wheat vernalization gene VRN1. Proc. Natl. Acad. Sci. USA 100:6263-6268. doi:10.1073/pnas.0937399100

Yu, J., J.B. Holland, M.D. McMullen, and E.S. Buckler. 2008. Genetic design and statistical power of nested association mapping in maize. Genetics 178:539-551. doi:10.1534/genetics.107.074245

Yun, S.J., L. Gyenis, E. Bossolini, P.M. Hayes, I. Matus, K.P. Smith, et al. 2006. Validation of quantitative trait loci for multiple disease resistance in barley using advanced backcross lines developed with a wild barley. Crop Sci. 46:1179-1186. doi:10.2135/ cropsci2005.08-0293

Zhang, Z., E. Ersoz, C.Q. Lai, R.J. Todhunter, H.K. Tiwari, M.A. Gore, et al. 2010. Mixed linear model approach adapted for genome-wide association studies. Nat. Genet. 42:355-360. doi:10.1038/ng.546 